\title{
Review of the safety and efficacy of imiglucerase treatment of Gaucher disease
}

\author{
This article was published in the following Dove Press journal: \\ Biologics: Targets \& Therapy \\ 25 August 2009 \\ Number of times this article has been viewed
}

\section{Deborah Elstein \\ Ari Zimran \\ Gaucher Clinic, Shaare Zedek Medical Center, Jerusalem, Israel}

Correspondence: Deborah Elstein Gaucher Clinic, Shaare Zedek Medical Center, PO Box 3235, Jerusalem 9103I, Israel

Tel +972-2-655-5093

Fax +972-2-65I-7979

Email elstein@szmc.org.il

\begin{abstract}
Most patients who suffer from symptomatic Gaucher disease will benefit from enzyme replacement therapy (ERT) with imiglucerase. The safety profile is excellent, only a small percentage of those exposed developing antibodies; similarly, very few patients require pre-medication for allergic reactions. Within 3 to 5 years of imiglucerase therapy, best documented at doses of 30 to 60 units $/ \mathrm{kg} /$ infusion, hepatosplenomegaly can be expected to be reduced so that the liver volume will be maintained at 1 to 1.5 times normal (30\% to $40 \%$ reduction from advent of ERT) and spleen volume to $\leq 2$ to 8 times normal ( $50 \%$ to $60 \%$ reduction from advent of ERT). For anemic and thrombocytopenic patients, with 2 to 5 years of imiglucerase, hemoglobin levels are expected to be $\geq 11 \mathrm{~g} / \mathrm{dL}$ for women and children and $\geq 12 \mathrm{~g} / \mathrm{dL}$ for men; and platelet counts in patients with an intact spleen, depending on the baseline value, should approximately be doubled. Bone crises and bone pain but not irreversible skeletal damage will improve in most patients. Nonetheless, some features and some symptomatic patients apparently do not respond equally well and/or perhaps inadequately. The benefit for patients with the neuronopathic forms is primarily in improved visceral and hematological signs and symptoms. There are still several unresolved issues, the high per-unit cost being an important one, which have spurred the development of biosimilar enzymes as well as chaperone therapies currently in clinical trials.
\end{abstract}

Keywords: Gaucher disease, enzyme replacement therapy, imiglucerase, substrate reduction therapy, pharmacological chaperones, cost

\section{Introduction: Gaucher disease is a rare recessive disorder}

Gaucher disease, the most prevalent glycolipid storage disorder, is a result of the genetic defect in the lysosomal enzyme $\beta$-glucocerebrosidase, and consequent accumulation of substrate, glucocerebroside, in the monocyte-macrophage system. ${ }^{1}$ Clinical heterogeneity is attributable, to a large extent, to $(\sim 300)$ mutations within the glucocerebrosidase gene (located at chromosome 1q21); ${ }^{2}$ however, the importance of epigenetic and environmental influences are beginning to be appreciated. ${ }^{3}$ Three clinical forms have been delineated, based on absence (type 1) or presence (types 2 and 3) of neurological signs ${ }^{4}$ and categorization of this sort is useful when talking about management options and genetic counseling.

\section{Type I: non-neuronopathic form}

Type 1, the non-neuronopathic form, is the most prevalent, with an ethnic predilection among Ashkenazi Jews that may be due to a selective advantage which has not yet 
been identified. ${ }^{5}$ Many patients are virtually asymptomatic and are diagnosed incidentally. ${ }^{6}$ Age of onset of symptoms and disease course are variable even among patients homozygous for the common N370S (1226G) mutation which is considered mild and protective of neurological involvement. ${ }^{7}$ Anemia and/or thrombocytopenia are common findings on presentation. In children, height retardation may be noted. ${ }^{8}$ Osteopenia and Erlenmeyer flask deformity of the distal femur are common; ${ }^{9}$ symptomatic skeletal features are less prevalent, including "bone crises", osteonecrosis of joints, and pathological fractures. Various imaging modalities assess/quantify bone involvement, ${ }^{10,11}$ but pre-symptomatic prediction of onset and rate of progression of bone disease has not been achieved. Lung involvement, especially infiltrative disease, is an uncommon but serious complication usually in splenectomized patients with liver involvement. Although the N370S mutation was considered to confer protection from neurological involvement, patients with this mutation may be at increased risk for parkinsonism ${ }^{12,13}$ and/or may develop peripheral nerve abnormalities. ${ }^{14,15}$

\section{Type 2: acute perinatal lethal neuronopathic form}

Type 2 is a lethal neuronopathic form usually associated with compound heterozygosity for a severe mutation and a null mutation, ${ }^{16-18}$ characterized by hypertonic posturing, strabismus, trismus, and retroflexion of the head during the first 6 months of life and death following aspiration pneumonia and/or apnea/laryngospasm by 2 years. ${ }^{19}$ Massive hepatosplenomegaly and lung involvement are usually seen. ${ }^{16}$

\section{Type 3: sub-acute neuronopathic form with three variants}

Type 3 is the more heterogeneous neuronopathic form, presenting in childhood and characterized by the pathognomonic sign of horizontal supranuclear gaze palsy (HSGP). ${ }^{20}$ Most patients have at least one L444P (1448C) mutation. Sub-classification of this form is based on relative prominence of neurological versus visceral findings. ${ }^{21}$ Type $3 \mathrm{a}$ patients exhibit mild-to-moderate hepatosplenomegaly and slowly progressive neurologic deterioration; recurrent myoclonic seizures are common. Type $3 \mathrm{~b}$ has aggressive visceral involvement but only HSGP; and type $3 \mathrm{c}$ is marked by homozygosity for the D409H (1342C) mutation, mild visceral disease, HSGP, and importantly, progressive and fatal calcifications of left heart (mitral and aortic) valves, aorta, and other arteries. ${ }^{22}$
Nonetheless, while it serves the purposes of this review to maintain demarcations between disease types to highlight the potential effects of therapeutic interventions, one may also view Gaucher phenotypes as a continuum of clinical manifestations that obscures rigid classifications. ${ }^{23}$

\section{Surrogate markers to assess efficacy of interventions}

Although amelioration of disease-specific symptoms and/or signs, eg, reduction in hepatosplenomegaly and improved blood counts, is a natural measure of efficacy of treatment, because of variability of response and/or the extended time-course to achieve a measureable response in diseasespecific symptoms, chitotriosidase activity levels which are elevated hundreds-fold in Gaucher disease, have been used in the past decade as the preferred surrogate marker. ${ }^{24}$ But, because of genetic deficiency of chitotriosidase in $\sim 6 \%$ of the population, CCL 18 (PARC) levels are additionally evaluated ${ }^{25}$ and research is ongoing to indentify novel biomarkers that would better predict bony complications. Some clinicians use these surrogate markers as a guide to initiation of treatment and/or dosage changes.

\section{Enzyme replacement therapy (ERT): the early years}

Nearly 50 years ago DeDuve suggested that lysosomal storage disease may be treatable by enzyme replacement. ${ }^{26}$ With the development of adequate purification techniques, glucocerebrosidase was derived from human placental tissue; ${ }^{27}$ subsequent deglycosylation to expose mannose residues $^{28}$ targeted the product to mannose receptors on the macrophages. ${ }^{29}$ Commercialization resulted in the development of alglucerase (Ceredase ${ }^{\circledR}$; Genzyme Inc., Cambridge, MA, USA), the placental derivative, which was tested in a seminal 9-month clinical trial of 12 patients with type 1 disease. ${ }^{30}$ Within the first 5 years of alglucerase, its safety and efficacy in improving hemoglobin levels and platelet counts, and in reducing splenic and hepatic enlargement were affirmed.

In 1994, the human recombinant form, imiglucerase (Cerezyme $^{\circledR}$; Genzyme Inc, Cambridge, MA, USA), was approved based on two clinical trials: the first comparing safety and efficacy of imiglucerase with alglucerase, at (high-dose) regimen of 60 units/kg body weight/ 2 weeks, ${ }^{31}$ the second compared frequency of administration of imiglucerase, every 2 weeks versus 3 times a week, at (low-dose) 15 units/kg body weight. ${ }^{32}$ Conclusions noted no significant differences between and among the groups. 
Imiglucerase gradually replaced alglucerase, which is only available today for a handful of patients who are unable to tolerate imiglucerase.

\section{Assessment modalities to quantify change: recommendation to reduce use less commonly available resources and decrease invasive modalities for routine evaluations}

At minimum, monitoring disease expression and effects of ERT includes serial evaluation of hematological parameters and reduction in hepatosplenomegaly. Although ultrasonography may be recommended for repeat assessments as the least invasive and as having no risk of radiation, ${ }^{33}$ especially in children, ${ }^{34}$ it is the least used because of issues of reliability and reproducibility and the importance of observer experience. Computed tomography (CT) was universally employed in the past,$^{35}$ and today, magnetic resonance imaging (MRI), ${ }^{36}$ especially because of justifiable concerns about radiation with periodic assessments is preferred. Similarly, scintigraphy ${ }^{37}$ is rarely employed.

The most accurate but least available tool for the bones is quantitative chemical shift imaging (QCSI). ${ }^{38}$

There are several bone and skeletal assessment scores, ${ }^{39-42}$ in addition to actual bone densitometry ${ }^{42,43}$ and bone marker ${ }^{42}$ evaluations. Echocardiography ${ }^{44}$ is recommended for follow-up of pulmonary hypertension. There are also specific tools for quality of life $\mathrm{e}^{45}$ assessment and cognitive function ${ }^{46}$ which are optimal for clinical trials rather than routine evaluations. In children, assessments are ageappropriate ${ }^{47}$ and in patients with type 3 disease, cognitive functioning ${ }^{48}$ is important as well.

Based on years of experience, the Gaucher community may/should re-consider the need for minutely accurate routine spleen and liver volumes (not in clinical trials) and rely on physical examination and ultrasonography combined with improved hematology and bio-markers for routine evaluations of patients.

\section{The Gaucher registry and "therapeutic goals": benchmarks for optimal management?}

Since 1991, the Genzyme Corporation has sponsored an international database of global outcome assessments, the International Collaborative Gaucher Group (ICGG). What was originally a commitment of the manufacturer to regulatory agencies for post-marketing surveillance, has evolved into a powerful tool of information about patient care. Published reports with ICGG data highlight patient demographics, and safety and efficacy of imiglucerase, ${ }^{49}$ as well as enable regulatory adjustments such as addition of type 3 to drug indications and modification regarding imiglucerase in pregnancy (see below). Indirectly, the almost predictable efficacy of imiglucerase has resulted in a new tool for assessing outcome. Based on ICGG input, the concept of therapeutic goals was introduced. ${ }^{50}$ These benchmarks reflect past experience in treated patients registered in the ICGG, but imply that future competitors may have to improve upon these outcomes to compete/supersede imiglucerase as standard care.

\section{“Therapeutic goals" for ERT}

The findings/expectations ${ }^{51}$ regarding hepatosplenomegaly are to reduce and maintain liver volume 1 to 1.5 times normal (by $30 \%$ to $40 \%$ by years 3 to 5 of ERT) and reduce and maintain spleen volume $\leq 2$ to 8 times normal (by $50 \%$ to $60 \%$ by years 2 to 5 of ERT). For achievement of the therapeutic goals for anemic and thrombocytopenic patients, the findings/ expectations respectively for hemoglobin are $\geq 11 \mathrm{~g} / \mathrm{dL}$ for women and children and $\geq 12 \mathrm{~g} / \mathrm{dL}$ for men; and for platelet counts in patients with an intact spleen and depending on the baseline value, a 1.5 to 2.0 fold-increase or doubling of counts by years 2 to 5 of ERT but not necessarily normalization of counts.

More recently, Weinreb et $\mathrm{l}^{52}$ presented the accumulated experience of the ICGG registry in achieving the above four goals. After 4 years of ERT, the findings in 195 patients (who were chosen based on various criteria and of sufficient data points but who are claimed to be representative of the entire cohort of 4760 patients) in achieving said goals was $23.6 \%$ to $54.9 \%$. There were two additional therapeutic goals, reduction in bone pain and bone crises, but it is still unclear whether ERT directly impacts these symptoms: most patients at baseline do not suffer from bone crises (episodes of bone pain that are localized and self-limiting); however, many patients suffer chronic bone pain, but achievement of this goal was the most modest (7.7\%) of the six parameters evaluated..$^{52}$ Nonetheless, other registry-based studies have shown significant improvements in bone parameters within 4 years of ERT. ${ }^{53}$ Children assessed in a separate study showed equally impressive improvements in the visceral response and linear growth. ${ }^{54}$

Therapeutic goals for hemoglobin improvement and liver volume reduction ie, the less Gaucher-specific parameters were more often met than for splenic volume and platelet counts which are more specifically characteristic of Gaucher disease. ${ }^{1}$ 
Finally, the impact of alglucerase/imiglucerase on the surrogate markers, chitotriosidase ${ }^{55}$ and CCL 18 (PARC) ${ }^{56}$ has lent credibility to their reliability to track interventions.

\section{ERT for bone disease}

Among patients from the seminal alglucerase trial radiological evidence of skeletal change was noted only 42 months after advent of therapy, ${ }^{57,58}$ but pathological damages (eg, osteonecrosis, bone infarcts, fractures) were not reversed. Importantly, improved MRI signals with ERT are not necessarily clinically relevant since no definitive correlation exists between MRI findings and incidence/severity of skeletal complications such as avascular necrosis. ${ }^{59}$

The most probable advantage for patients prone to bone disease (beyond not undergoing total ${ }^{60}$ or partial splenectomy), ${ }^{61}$ is early administration of ERT as preventative, especially in children. ${ }^{62}$ This premise is based on fewer cases of avascular necrosis among children born after ERT availability relative to children growing up before availability of ERT. ${ }^{62}$ The challenge is still how to identify children at risk during the pre-symptomatic stage of the disease. This is particularly difficult in patient homozygous for the N370S mutation.

Osteopenia is not uncommon in the general population but apparently progression to osteoporosis, ie, decreased bone mineral density (BMD) as generally estimated by dual-energy X-ray absorptiometry (DEXA), is characteristic of adults with Gaucher disease. ${ }^{63}$ Imiglucerase (60 units $/ \mathrm{kg} / 2$ weeks) significantly improves BMD in adult patients with improvement of BMD at the lumbar spine ${ }^{64}$ and femoral neck $^{65}$ after $>3$ to 4 years. Moreover, biochemical markers for bone formation increased, markers for bone resorption decreased, with resolution of bone crises, decreased bone pain, and fewer skeletal complications. ${ }^{65}$

In summary, it cannot be said with absolute certainty that ERT will prevent or reverse skeletal complications.

\section{Co-administration of imiglucerase and alendronate for bone involvement}

Bisphosphonates are well-documented as effective in increasing BMD in at-risk adult populations. ${ }^{66} \mathrm{~A}$ clinical trial of co-administration of imiglucerase with oral alendronate (40 mg/day) in adult patients proved that combined therapy was significantly better for Gaucher-related osteopenia relative to imiglucerase alone, although skeletal lesions remained irreversible.$^{67}$ However, this placebo-controlled prospective study unfortunately did not include an alendronate-only arm which may have been equally effective. This speculation is based on the authors' experience with osteopenic/ osteoporotic patients without other significant Gaucherrelated signs/symptoms, who have demonstrated impressive improvement in BMD using bisphosphonates and calcium supplementation alone.

It may be posited therefore that while various facets of bone disease in patients with Gaucher disease are specific Gaucher signs and theoretically amenable to ERT, there are a myriad of epigenetic and environmental factors, comparable to those seen in healthy populations, ${ }^{68}$ that impact a global marker such as BMD, and hence ERT would not be expected to completely correct all deficits.

Another tenable hypothetical construct is that the large enzyme molecules are equally incapable of traversing the blood-brain barrier as the small blood vessels of bony matrix and/or Gaucher-cell-infiltrated marrow which may have the character of immortalized cells and/or dead tissue. Be that as it may, preventing bone involvement and reversing destructive processes of (type 1 and type 3) Gaucher disease, remains unresolved. ${ }^{69}$

\section{Other uncommon sites of Gaucher involvement where the effect of enzyme replacement is imperfect: lung and brain}

The earliest report of ERT in severely affected patients with non-neuronopathic disease and infiltrative lung involvement reported improved functioning, ${ }^{70}$ but not always of clinical significance. ${ }^{71}$ Children with type $2^{72}$ or type $3^{73}$ neuronopathic disease who are more prone to pulmonary complications, generally showed no improvement in pulmonary features with ERT.

Pulmonary hypertension $(\mathrm{PH})$ has been noted in some patients on ERT. It has been suggested that there is a predisposition for $\mathrm{PH}$ in patients with type 1, especially in the presence of additional genetic factors and epigenetic modifiers. ${ }^{74}$ Others have suggested a causal relationship ${ }^{44}$ between PH and ERT, particularly among young splenectomized women, but this has been difficult to prove. Treatment withdrawal may be considered in these patients who evince primary-like $\mathrm{PH}$ and progressive increases in TI gradient $(>30 \mathrm{mmHg}$ ) with ERT during routine echocardiographic monitoring. Alternatively, adding PH-specific therapy to ERT has also been beneficial. ${ }^{75}$

As implied, ERT cannot be expected to change the natural course of neurological progression in type 2 disease $^{76}$ or type 3 disease $^{77}$ regardless of dosage regimens. 


\section{Summary of the clinical efficacy of imiglucerase}

In summary, and with 15 years of experience with imiglucerase, the important conclusion seems to be that at advent of therapy most patients suffer from several clinically relevant signs and symptoms of Gaucher disease, and that these gradually ( 2 to 5 years) improve with exposure to ERT so that near-normalization of many parameters is possible, although some parameters or perhaps some segment of the bell-curve of symptomatic patients, do not respond equally well or perhaps not even adequately. Those patients with neurological features will probably only see benefit in improved visceral and hematological signs and symptoms.

\section{Safety of imiglucerase}

Most of the side effects listed for alglucerase and imiglucerase during the clinical trials and afterwards, were infrequently observed, typically mild, and almost always transient in nature. This excellent safety has allowed home therapy in many countries, ${ }^{78,79}$ and the administration of ERT during pregnancy despite the original warning in the package insert. ${ }^{80,81}$ The development of anti-glucocerebrosidase antibodies has been reported to occur among $15 \%$ of patients ${ }^{82}$ primarily non-neutralizing IgG antibodies.

\section{Unresolved issues}

There were some concerning issues that were raised by clinicians based on patient reports: some related to the prevalence and impact of side effects of ERT such as weight gain and diabetes and metabolic syndrome-like conditions; ${ }^{83}$ or evolution of neurological symptoms in type 1 patients; $;{ }^{84}$ the incidence of new bony complications in treated patients; ${ }^{85,86}$ and severe allergic reactions ${ }^{87}$ requiring pre-medication for infusions and the adverse related to both infusions per se and the pre-medications.

Recently, it has been implied that there is an increased risk for cancer among patients with the N370S allele ${ }^{88}$ and that there is also decreased survival among patients with type 1 disease which is ascribed to cancers, as well as cardiovascular and cerebrovascular events, ${ }^{89}$ the latter heretofore not having figured prominently as Gaucher-specific signs, and unexplainable based on studies of lipid-cholesterol profiles in Gaucher disease. ${ }^{90}$ These potentially immunologically based events have raised theoretical concerns about the nature of glucocerebroside storage and its potentially beneficial ramifications. ${ }^{91}$ Because of the putative association of ERT with increased rates of malignancy, immune mediated disorders, and altered metabolic pathways ERT although indicated for patients with moderate to severe disease, may not be justified in patients with very mild disease. ${ }^{91}$

The dosage controversy has never been adequately resolved..$^{92,93}$ The first and possibly overriding concern was the cost, but beyond this was the question of whether higher doses actually translate into more effective therapy. ${ }^{94}$ Moreover, as the above concerns about the inimical aspects of ERT and particularly high-dose ERT are raised, and the question of indications for therapy re-evaluated, the concept of maintenance regimens and/or (intermittent or complete) withdrawa ${ }^{95,96}$ and not just dose adjustments ${ }^{97}$ after achieving near-normalization of hematological and visceral parameters with ERT should also be re-considered.

\section{Important unresolved issues that spur the initiatives for new modalities: cost}

Cost remains a critical constraint in providing imiglucerase to symptomatic patients, although it must be noted that the Genzyme Corporation has been generous with a worldwide programs for compassionate use. However, expensive therapy for a potentially non-lethal disease such as type 1 Gaucher disease has both ethical ramifications ${ }^{98}$ because of issues of scarce resources, as well as economic considerations because national health budgets ${ }^{99}$ that subsidize expensive therapies are prioritized by societal value systems. Cost per unit is high; the manufacturer recommended regimen is highdose; asymptomatic patients are treated prophylactically; and there is a commitment to life-long treatment because maintenance regimens at lower doses and/or drug vacations are not sanctioned. Thus, a less expensive enzyme, potentially safe and effective as imiglucerase, would be an attractive option and this despite the above clinically-relevant qualifiers

\section{Biosimilar enzymatic preparations}

Both Shire Human Genetics Therapies (Cambridge, MA, USA) and Protalix Pharmaceuticals (Carmiel, Israel) are currently in clinical trials with respective infusible enzyme therapies and are preparing New Drug Administration submissions to the FDA. The Shire enzyme, velaglucerase alfa, has the advantages of being produced in a human cell line and having the normal human sequence ${ }^{100}$ (imiglucerase has a point mutation) while the Protalix enzyme uses a high-yield plant cell system that is easily up-scalable in disposable bioreactors and free from any exposure to mammalian tissues. ${ }^{101}$ Both are being tested at two doses and in treatment-naïve patients as well as in patients who had been exposed to imiglucerase; velaglucerase alfa also has a head-to-head comparison 
with imiglucerase at the high-dose regimen. Because being dependent on a single source for therapy is not desirable, even for rare diseases, comparable treatments should be encouraged. Should these biosimilars actualize their potential as equally safe and comparably effective as imiglucerase plus be less expensive, they would be well-positioned to capture some of the imiglucerase market share.

\section{Other therapeutic modalities: substrate reduction (inhibition) therapy}

In 1996, Radin suggested that enzyme therapy, a "spectacularly expensive mode of treatment should be replaceable with a suitable enzyme inhibitor that simply slows formation of the lipid, and matches the rate of synthesis with the rate of the defective, slowly working beta-glucosidase". ${ }^{102}$ The iminosugar $N$-butyl deoxynojirimycin (miglustat), an inhibitor of glucosyltransferase, the first committed step in the biosynthesis of glycolipids, was a harbinger of this new class of oral substrate inhibitors for lysosomal storage diseases but also indirectly introduced pharmacological chaperoning as a therapeutic modality (see below). Because of its more problematic safety profile, miglustat (Zavesca $^{\circledR}$; Actelion Pharmaceuticals) was approved by the EMEA (2002) only for adult patients with mild to moderate disease unsuitable for standard enzyme therapy and by the FDA (2003) with a similar caveat, for adults for whom ERT is not a therapeutic option. In addition, miglustat therapy showed improved BMD as early as 6 months after advent of therapy. ${ }^{103}$

In a switch-over trial that evaluated miglustat in patients clinically stable on imiglucerase, tolerability of miglustat and imiglucerase, alone and in combination, pharmacokinetic profile, organ reduction, and chitotriosidase activity were assessed. Combination therapy did not show a clinically significant benefit. ${ }^{104}$

In retrospect, one might raise the question why combination therapy would be recommended for type 1 disease, but the lack of interference between modalities may be noteworthy. On the other hand, for type 3 disease, small molecule therapy also has the potential to cross the bloodbrain barrier; ${ }^{105}$ but in the case of miglustat, it was not less expensive and the clinical trial failed to meet the primary end point and/or to make a substantial impact on neuronopathic features of the disease. The clinical trial recruited patients with type 3 disease receiving (high-dose) imiglucerase and added miglustat (200 mg, tid); ${ }^{106}$ but a single case report of an adult, after 2 years of combined miglustat (200 mg, tid) and imiglucerase (60 units/kg/2 weeks), showed fewer tonic-clonic seizures and speech improved. ${ }^{107}$

\section{A ceramide analog as SRT}

The Genzyme Corporation has begun clinical trials with substrate reduction therapy with GENZ 112638 a ceramide analog of the substrate (rather than the sugar moiety as in miglustat). To date, preliminary results of efficacy are very encouraging with improvement in key clinical parameters, including bone, in patients with type 1 disease. Unlike miglustat, this compound is probably incapable of traversing the blood-brain barrier. Phase 3 trials will be recruiting in the 2009 to 2010 quartiles.

\section{Other therapeutic modalities: chaperone therapy}

"Enzyme enhancement therapy" or "chaperone-mediated therapy" offers a novel therapeutic strategy to increase residual function of mutant proteins. Enhancement of the mutant enzyme is achieved by employing small molecules to properly traffic mis-folded and/or unstable mutant enzymes from the endoplasmic reticulum (ER) ${ }^{108}$ and prevent ER-associated degradation in proteasomes. ${ }^{109}$ This therapeutic approach is especially applicable to Gaucher disease because only a modest increase in residual glucocerebrosidase is sufficient to ameliorate the clinical phenotype. ${ }^{110}$ Small molecule chaperones should be able to cross the blood-brain barrier.

The first potent in vitro inhibitor of glucocerebrosidase that met criteria as a pharmacological chaperone was isofagomine tartrate. It proved to be active-site-specific and capable of increasing residual glucocerebrosidase activity in fibroblasts (from patients with Gaucher disease) with the N370S mutation. ${ }^{111}$ Recent reports of the clinical safety of isofagomine (commercial name: Plicera ${ }^{\mathrm{TM}}$ ) in a phase 2 trial by Amicus Therapeutics (Cranberry, NJ, USA) show good tolerability and safety. However, the patients were those on ERT who discontinued for a 4-week period only in order to participate in the current trial; this may be insufficient to extrapolate that clinical parameters were maintained, since there was no period of ERT wash-out, and hence no information can be derived from this trial about efficacy; this awaits the report of the phase 2 trial in patients naïve to treatment. Experience with patients who had received ERT for varying periods and then had withdrawn from ERT for varying periods, showed a very slow wash-out of the beneficial effects that had accrued from ERT. ${ }^{95}$

A second pharmacological chaperone is ambroxol hydrochloride (ExSAR Corporation, Princeton Junction, NJ, USA). 
A high-throughput screen of chemical compound libraries identified this non-carbohydrate-based inhibitory molecule capable of raising glucocerebrosidase activity in fibroblasts (from patients with Gaucher disease) with the N370S mutation and the more rare F213I mutation; comparable fibroblasts treated with ambroxol had decreased levels of glucocerebrosidase in the ER and increased levels in lysosomes. ${ }^{12,113}$ Ambroxol was originally developed as a mucolytic agent (Mucosolvan ${ }^{\circledR}$; Boehringer Ingelheim $\mathrm{GmbH}$, Ingelheim, Germany) to improve expectoration in conditions associated with viscid mucus ${ }^{114}$ but also promotion of prenatal lung maturation and prophylaxis against newborn respiratory distress syndrome. ${ }^{115}$ An investigator-initiated pilot study with ambroxol in patients with type 1 Gaucher disease was begun in 2009 at the Shaare Zedek Medical Center.

Diltiazem, an inhibitor of L-type $\mathrm{Ca}(2+)$ channels, at neutral $\mathrm{pH}$ as found in the ER was also shown to exhibit biochemical characteristics of a glucocerebrosidase pharmacological chaperone: in vitro it increased enzyme activity in normal cells, in N370S/N370S and other Gaucher mutant cells. ${ }^{116}$ This drug is currently administered to patients with type 3 disease in the UK as another investigator-initiated study.

\section{The ethical dilemma of expensive non-curative drugs for rare diseases}

In discussing the successes of imiglucerase, it would be remiss not to highlight the medical ethical dilemma of an expensive non-curative drug such as imiglucerase for a rare but not lethal disease such as Gaucher disease. It is obvious that this allocation precludes availability of ever-more limited financial resources for more common and more fatal disorders. In 1983, the American Congress by virtue of the legal imperative of the Orphan Drug Act (similar legislation was subsequently enacted in Europe and Japan) encouraged clinical research into the several thousand "orphan" disorders each of which affects fewer than 200,000 Americans, by offering tax breaks and exclusive marketing rights. The reality of this legislation was to give pharmaceutical companies brave enough to invest in "orphan drugs" that finally make it to the pharmacy shelf, a captive audience whose only drug of choice was often personally unaffordable. Although no society would elect to curtail treatment on the basis of cost in the case of abundance of resources, this is not the reality in any country in the world today. Thus, whereas one applauds the ultimately humanitarian outcome of underwriting medical research into diseases that had heretofore been neglected because few patients were involved, the phenomenon of a single "gold standard" treatment is no longer realistic nor desirable: per unit cost matters a lot. Moreover, in the case of type 1 Gaucher disease where patients have enjoyed imiglucerase therapy for 15 years, the concept of a plateauing of the clinical response is no longer dismissed: there are good responders, ie, those achieving near-normalization of the key clinical parameters within 2 to 5 years, and there are also less good responders who do not derive a complete clinical remission. There are those with brain, bone, and lung signs and symptoms that have emerged, whether before treatment or whether while on ERT, whose disease progresses in these organs and whose quality of life is considerably impaired. Indeed, there is the difficult question of whether ERT is ethically condonable in type 2 Gaucher disease. ${ }^{117}$ For this reason, the interest in new formulations and new modalities is a sign of the economics of our time, but also an appreciation of the fact that ERT is not the ultimately best resolution for all patients with the various forms of Gaucher disease.

\section{Conclusion: hopes for the future}

Clearly, all the above therapeutic modalities miss the point of providing a cure: although maintenance regimens have not been addressed, it is probable that symptomatic patients will continue to need specific therapy for Gaucher disease over the course of a lifetime. It is also manifestly clear that once brain, bone, and lung involvement become symptomatic, the probability of any of the above modalities to reverse the pathology is low indeed. Only gene therapy ${ }^{118}$ may prevent emergence of any symptoms and would be curative for all forms of the disease as well. Bone marrow transplantation (BMT) has been used in the past, ${ }^{119}$ albeit in limited cases and mostly in children with type 3 disease, in order to ameliorate the enzyme deficiency by providing enzyme competent cells from the donor marrow. Enzyme levels were restored and glucocerebroside levels in plasma were normalized one year after BMT in all the engrafted patients, ${ }^{120}$ but this modality has been abandoned in non-neuronopathic Gaucher disease because of its inherent risks for a non-life-threatening disorder. Studies of human CD34 cells were carried out to evaluate their potential use in a gene therapy approach to Gaucher disease and trials in humans were initiated. ${ }^{121,122}$ Unhappily progress has been erratic and new clinical trials in patients with Gaucher disease are not yet on the horizon. However, based on a new murine model of type 1 Gaucher disease and using low-risk conditioning regimens (non-myeloablative doses of busulfan) there have been encouraging data that only a low level of normal or gene-corrected cells with engraftment can induce a beneficial therapeutic outcome. ${ }^{123}$ 


\section{Abbreviations}

BMD, bone mineral density; BMT, bone marrow transplantation; CT, computed tomography; DEXA, dual-energy X-ray absorptiometry; EMEA, European Medicines Agency; ER, endoplasmic reticulum; ERT, enzyme replacement therapy; FDA, (US) Food and Drug Administration; HSGP, horizontal supranuclear gaze palsy; ICGG, International Collaborative Gaucher Group; MRI, magnetic resonance imaging; PH, pulmonary hypertension; QCSI, quantitative chemical shift imaging; SRT, substrate reduction therapy; TI, tricuspid insufficiency; tid, three times a day.

\section{Disclosures}

DE receives consulting fees from Shire HGT. AZ receives consultancy fees from Shire Human Genetic Therapies; receives consultancy fees and has options in Protalix Therapeutics and sits on their Scientific Advisory Board; receives support from Genzyme Therapeutics for participation in the ICGG registry.

\section{References}

1. Beutler E, Grabowski GA. Gaucher disease. In: Scriver CR, Beudet AL, Sly WS, editors. The Metabolic and Molecular Basis of Inherited Disease. New York: McGraw-Hill; 2001:3635-3668.

2. Hruska KS, LaMarca ME, Scott CR, Sidransky E. Gaucher disease: mutation and polymorphism spectrum in the glucocerebrosidase gene (GBA). Hum Mutat. 2008;29(5):567-583.

3. Goker-Alpan O, Hruska KS, Orvisky E, et al. Divergent phenotypes in Gaucher disease implicate the role of modifiers. J Med Genet. 2005;42(6):e37.

4. Knudson AG, Kaplan WD. Genetics of the sphingolipidoses. In: Aronson SM, Volk BW, eds. Cerebral Sphingolipidoses. New York: Academic Press. 1962:395.

5. Grabowski GA, Horowitz M. Gaucher's disease: molecular, genetic and enzymological aspects. Baillieres Clin Haematol. 1997;10(4):635-656.

6. Azuri J, Elstein D, Lahad A, Abrahamov A, Hadas-Halpern I, Zimran A. Asymptomatic Gaucher disease implications for large-scale screening. Genet Test. 1998;2(4):297-299.

7. Fairley C, Zimran A, Phillips M, et al. Phenotypic heterogeneity of N370S homozygotes with type I Gaucher disease: an analysis of 798 patients from the ICGG Gaucher Registry. J Inherit Metab Dis. 2008;31(6):7387-7744.

8. Kaplan P, Andersson HC, Kacena KA, et al. The clinical and demographic characteristics of nonneuronopathic Gaucher disease in 887 children at diagnosis. Arch Pediatr Adolesc Med. 2006;160(6): 603-608.

9. Stowens DW, Teitelbaum SL, Kahn AJ, et al. Skeletal complications of Gaucher's disease. Medicine. 1985;64(5):310-322.

10. Hermann G, Goldblatt J, Levy RN, Goldsmith SJ, Desnick RJ, Grabowski GA. Gaucher's disease type 1: assessment of bone involvement by CT and scintigraphy. AJR Am J Roentgenol. 1986;147(5): 943-948.

11. Maas M, Hollak CE, Akkerman EM, Aerts JM, Stoker J, Den Heeten GJ. Quantification of skeletal involvement in adults with type I Gaucher's disease: fat fraction measured by Dixon quantitative chemical shift imaging as a valid parameter. AJR Am J Roentgenol. 2002;179(4):961-965.

12. Neudorfer O, Giladi N, Elstein D, et al. Occurrence of Parkinson's syndrome in type I Gaucher disease. $Q J$ Med. 1996;89:691-694.
13. Lwin A, Orvisky E, Goker-Alpan O, LaMarca ME, Sidransky E. Glucocerebrosidase mutations in subjects with parkinsonism. Mol Genet Metab. 2004;81(1):70-73.

14. Pastores GM. Musculoskeletal complications encountered in the lysosomal storage disorders. Best Pract Res Clin Rheumatol. 2008;22(5):937-947.

15. Biegstraaten M, van Schaik IN, Aerts JM, Hollak CE. 'Nonneuronopathic' Gaucher disease reconsidered. Prevalence of neurological manifestations in a Dutch cohort of type I Gaucher disease patients and a systematic review of the literature. J Inherit Metab Dis. 2008; 31(3):337-349.

16. Brady RO, Barton NW, Grabowski GA. The role of neurogenetics in Gaucher disease. Arch Neurol. 1993;50(11):1212-1224.

17. Beutler E, Gelbart T. Hematologically important mutations: Gaucher disease. Blood Cells Mol Dis. 1998;24(1):2-8.

18. Stone DL, Carey WF, Christodoulou J, et al. Type 2 Gaucher disease: the collodion baby phenotype revisited. Arch Dis Child Fetal Neonatal Ed. 2000;82(2):F163-F166.

19. Mignot C, Doummar D, Maire I, De Villemeur TB; French Type 2 Gaucher Disease Study Group. Type 2 Gaucher disease: 15 new cases and review of the literature. Brain Dev. 2006;28(1):39-48.

20. Tylki-Szymañska A, Keddache M, Grabowski GA. Characterization of neuronopathic Gaucher disease among ethnic Poles. Genet Med. 2006;8(1):8-15

21. Patterson MC, Horowitz M, Abel RB, et al. Isolated horizontal supranuclear gaze palsy as a marker of severe systemic involvement in Gaucher's disease. Neurology. 1993;43(10):1993-1997.

22. Abrahamov A, Elstein D, Horowitz M, et al. A new Gaucher disease variant characterized by progressive calcification of heart valves and unique genotype. Lancet. 1995;346(8981):1000-1003.

23. Goker-Alpan O, Schiffmann R, Park JK, Stubblefield BK, Tayebi N, Sidransky E. Phenotypic continuum in neuronopathic Gaucher disease: an intermediate phenotype between type 2 and type 3. J Pediatr. 2003; 143(2):273-276.

24. Hollak CEM, van Weely S, van Oers MHJ, Aerts JMFG. Marked elevation of plasma chitotriosidase activity. A novel hallmark of Gaucher disease. J Clin Invest. 1994;93(3):1288-1292.

25. Boot RG, Verhoek M, de Fost M, et al. Marked elevation of the chemokine CCL18/PARC in Gaucher disease: a novel surrogate marker for assessing therapeutic intervention. Blood. 2004;103(1):33-39.

26. DeDuve C. From cytases to lysosomes. Fed Proc. 1964;23:1045-1049.

27. Pentchev PG, Brady RO, Hibbert $\mathrm{S}$, et al. Isolation and characterization of glucocerebrosidase from human placental tissue. $J$ Biol Chem. 1973;248(15):5256-5261

28. Furbish FS, Oliver KL, Zirzow GC, et al. Uptake and distribution of placental glucocerebrosidase in rat hepatic cells and effects of sequential deglycosylation. Biochim Biophys Acta. 1981;673(4):425-434.

29. Achord DT, Brot FE, Bell CE, et al. Human beta-glucuronidase: in vivo clearance and in vitro uptake by a glycoprotein recognition system on reticuloendothelial cells. Cell. 1978;15(1):269-278.

30. Barton NW, Brady RO, Dambrosia JM, et al. Replacement therapy for inherited enzyme deficiency - macrophage-targeted glucocerebrosidase for Gaucher's disease. N Engl J Med. 1991;324(21):1464-1470.

31. Grabowski GA, Barton NM, Pastores G, et al. Enzyme therapy in Gaucher disease type 1: comparative efficacy of mannose-terminated glucocerebrosidase from natural and recombinant sources. Ann Int Med. 1995; 122(1):33-39.

32. Zimran A, Elstein D, Levy-Lahad E, et al. Replacement therapy with imiglucerase for type 1 Gaucher's disease. Lancet. 1995(8963); 345:1479-1480.

33. Patlas M, Hadas-Halpern I, Abrahamov A, Zimran A, Elstein D. Repeat abdominal ultrasound evaluation of 100 patients with type I Gaucher disease treated with enzyme replacement therapy for up to 7 years. Hematol J. 2002;3(1):17-20.

34. Patlas M, Hadas-Halpern I, Abrahamov A, Elstein D, Zimran A. Spectrum of abdominal sonographic findings in 103 pediatric patients with Gaucher disease. Eur Radiol. 2002;12(2):397-400. 
35. Hollak CE, Corssmit EP, Aerts JM, et al. Differential effects of enzyme supplementation therapy on manifestations of type 1 Gaucher disease. Am J Med. 1997;103(3):185-191.

36. Terk MR, Dardashti S, Liebman HA. Bone marrow response in treated patients with Gaucher disease: evaluation by T1-weighted magnetic resonance images and correlation with reduction in liver and spleen volume. Skeletal Radiol. 2000;29(10):563-571.

37. Lorberboym M, Pastores GM, Kim CK, Hermann G, Glajchen N, Machac J. Scintigraphic monitoring of reticuloendothelial system in patients with type 1 Gaucher disease on enzyme replacement therapy. J Nucl Med. 1997;38(6):890-895.

38. Hollak C, Maas M, Akkerman E, den Heeten A, Aerts H. Dixon quantitative chemical shift imaging is a sensitive tool for the evaluation of bone marrow responses to individualized doses of enzyme supplementation therapy in type 1 Gaucher disease. Blood Cells Mol Dis. 2001;27(6):1005-1012.

39. Hermann G, Pastores GM, Abdelwahab IF, Lorberboym AM. Gaucher disease: assessment of skeletal involvement and therapeutic responses to enzyme replacement. Skeletal Radiol. 1997;26(12):687-696.

40. Vom Dahl S, Poll L, Di Rocco M, et al. Evidence-based recommendations for monitoring bone disease and the response to enzyme replacement therapy in Gaucher patients. Curr Med Res Opin. 2006;22(6):1045-1064.

41. Robertson PL, Maas M, Goldblatt J. Semiquantitative assessment of skeletal response to enzyme replacement therapy for Gaucher's disease using the bone marrow burden score. AJR Am J Roentgenol. 2007;188(6):1521-1528.

42. Ciana G, Martini C, Leopaldi A, et al. Bone marker alterations in patients with type 1 Gaucher disease. Calcif Tissue Int. 2003;72(3):185-189.

43. Wenstrup RJ, Kacena KA, Kaplan P, et al. Effect of enzyme replacement therapy with imiglucerase on BMD in type 1 Gaucher disease. J Bone Miner Res. 2007;22(1):119-126.

44. Elstein D, Klutstein MW, Lahad A, Abrahamov A, Hadas-Halpern I, Zimran A. Echocardiographic assessment of pulmonary hypertension in Gaucher's disease. Lancet. 1998;351(9115):1544-1546.

45. Masek BJ, Sims KB, Bove CM, Korson MS, Short P, Norman DK. Quality of life assessment in adults with type 1 Gaucher disease. Qual Life Res. 1999;8(3):263-268.

46. Elstein D, Guedalia J, Doniger GM, et al. Computerized cognitive testing in patients with type I Gaucher disease: effects of enzyme replacement and substrate reduction. Genet Med. 2005;7(2):124-130.

47. Baldellou A, Andria G, Campbell PE, et al. Paediatric non-neuronopathic Gaucher disease: recommendations for treatment and monitoring. Eur J Pediatr. 2004;163(2):67-75.

48. Goker-Alpan O, Wiggs EA, Eblan MJ, et al. Cognitive outcome in treated patients with chronic neuronopathic Gaucher disease. J Pediatr. 2008;153(1):89-94.

49. Charrow J, Andersson HC, Kaplan P, et al. The Gaucher registry: demographics and disease characteristics of 1698 patients with Gaucher disease. Arch Intern Med. 2000;160(18):2835-2843.

50. Weinreb NJ. Introduction. Advances in Gaucher disease: Therapeutic goals and evaluation and monitoring guidelines. Semin Hematol. 2004;41(4 Suppl 5):1-3.

51. Pastores GM, Weinreb NJ, Aerts H, et al. Therapeutic goals in the treatment of Gaucher disease. Semin Hematol. 2004;41(4 Suppl 5):4-14.

52. Weinreb N, Taylor J, Cox T, Yee J, et al. A benchmark analysis of the achievement of therapeutic goals for type 1 Gaucher disease patients treated with imiglucerase. Amer J Hematol. 2008;83(12):890-895.

53. Charrow J, Dulisse B, Grabowski GA, Weinreb NJ. The effect of enzyme replacement therapy on bone crisis and bone pain in patients with type 1 Gaucher disease. Clin Genet. 2007;71(3):205-211.

54. Andersson H, Kaplan P, Kacena K, Yee J. Eight-year clinical outcomes of long-term enzyme replacement therapy for 884 children with Gaucher disease type 1. Pediatrics. 2008;122(6):1182-1190.

55. Czartoryska B, Tylki-Szymańska A, Górska D. Serum chitotriosidase activity in Gaucher patients on enzyme replacement therapy (ERT). Clin Biochem. 1998;31(5):417-420.
56. Deegan PB, Moran MT, McFarlane I, et al. Clinical evaluation of chemokine and enzymatic biomarkers of Gaucher disease. Blood Cells Mol Dis. 2005;35(2):259-267.

57. Rosenthal DI, Doppelt SH, Mankin HJ, et al. Enzyme replacement therapy for Gaucher disease: skeletal responses to macrophage-targeted glucocerebrosidase. Pediatrics. 1995;96(4 Pt 1):629-637.

58. Poll LW, Maas M, Terk MR, et al. Response of Gaucher bone disease to enzyme replacement therapy. Br J Radiol. 2002;75(Suppl 1): A25-A36.

59. de Fost M, Hollak CE, Groener JE, et al. Superior effects of high-dose enzyme replacement therapy in type 1 Gaucher disease on bone marrow involvement and chitotriosidase levels: a 2-center retrospective analysis. Blood. 2006;108(3):830-835.

60. Fleshner PR, Aufses AH Jr, Grabowski GA, Elias R. A 27-year experience with splenectomy for Gaucher's disease. Am J Surg. 1991; 161(1):69-75.

61. Zimran A, Elstein D, Schiffmann R, et al. Outcome of partial splenectomy for type I Gaucher disease. J Pediatr. 1995;126(4):596-597.

62. Zimran A, Abrahamov A, Elstein D. Children with type I Gaucher disease: growing into adulthood with and without enzyme therapy. Isr Med Assoc J. 2000;2(2):80-81.

63. Wenstrup RJ, Roca-Espiau M, Weinreb NJ, Bembi B. Skeletal aspects of Gaucher disease: a review. Br J Radiol. 2002;75(Suppl 1):A2-A12.

64. Wenstrup RJ, Kacena KA, Kaplan P, et al. Effect of enzyme replacement therapy with imiglucerase on BMD in type 1 Gaucher disease. J Bone Miner Res. 2007;22(1):119-126.

65. Sims KB, Pastores GM, Weinreb NJ, et al. Improvement of bone disease by imiglucerase (Cerezyme) therapy in patients with skeletal manifestations of type 1 Gaucher disease: results of a 48-month longitudinal cohort study. Clin Genet. 2008;73(5):430-440.

66. Fleurence RL, Iglesias CP, Johnson JM. The cost effectiveness of bisphosphonates for the prevention and treatment of osteoporosis: a structured review of the literature. Pharmacoeconomics. 2007;25(11): 913-933.

67. Wenstrup RJ, Bailey L, Grabowski GA, et al. Gaucher disease: alendronate disodium improves bone mineral density in adults receiving enzyme therapy. Blood. 2004;104(5):1253-1257.

68. Arnheim E, Chicco G, Phillips M, et al. Molecular aspects of osteopathy in type 1 Gaucher disease: correlation between genetics and bone density. Rheumatol Int. 2008;28(9):873-877.

69. Hůlková H, Ledvinová J, Poupětová $H$, Kohout A, Malinová V, Elleder M. Autopsy case of Gaucher disease type I in a patient on enzyme replacement therapy. Comments on the dynamics of persistent storage process. J Inherit Metab Dis. 2009 Jun 26. [Epub ahead of print].

70. Beutler E, Kay A, Saven A, et al. Enzyme replacement therapy for Gaucher disease. Blood. 1991;78(5):1183-1189.

71. Pastores GM, Sibille AR, Grabowski GA. Enzyme therapy in Gaucher disease type 1: dosage efficacy and adverse effects in 33 patients treated for 6 to 24 months. Blood. 1993;82(2):408-416.

72. Takahashi T, Yoshida Y, Sato W, et al. Enzyme therapy in Gaucher disease type 2: an autopsy case. Tohoku J Exp Med. 1998;186(2):143-149.

73. Altarescu G, Hill S, Wiggs E, et al. The efficacy of enzyme replacement therapy in patients with chronic neuronopathic Gaucher's disease. J Pediatr. 2001;138(4):539-547.

74. Mistry PK, Sirrs S, Chan A, et al. Pulmonary hypertension in type 1 Gaucher's disease: genetic and epigenetic determinants of phenotype and response to therapy. Mol Genet Metab. 2002;77(1-2):91-98.

75. Bove KE, Daugherty C, Grabowski GA. Pathological findings in Gaucher disease type 2 patients following enzyme therapy. Hum Pathol. 1995;26(9):1040-1045.

76. Davies EH, Erikson A, Collin-Histed T, Mengel E, Tylki-Szymanska A, Vellodi A. Outcome of type III Gaucher disease on enzyme replacement therapy: review of 55 cases. J Inherit Metab Dis. 2007;30(6): 935-942.

77. Starzyk K, Richards S, Yee J, Smith SE, Kingma W. The long-term international safety experience of imiglucerase therapy for Gaucher disease. Mol Genet Metab. 2007;90(2):157-163. 
78. Zimran A, Hollak CE, Abrahamov A, van Oers MH, Kelly M, Beutler E. Home treatment with intravenous enzyme replacement therapy for Gaucher disease: an international collaborative study of 33 patients. Blood. 1993;82(4):1107-1109.

79. Milligan A, Hughes D, Goodwin S, Richfield L, Mehta A. Intravenous enzyme replacement therapy: better in home or hospital? Br J Nurs. 2006;15(6):330-333.

80. Elstein D, Granovsky-Grisaru S, Rabinowitz R, Kanai R, Abrahamov A, Zimran A. Use of enzyme replacement therapy for Gaucher disease during pregnancy. Am J Obstet Gynecol. 1997;177(6):1509-1512.

81. Zimran A, Morris E, Mengel E, et al. The female Gaucher patient: The impact of enzyme replacement therapy around key reproductive events (menstruation, pregnancy and menopause). Blood Cells Mol Dis. 2009 Jun 5. [Epub ahead of print].

82. Weinreb NJ, Charrow J, Andersson HC, et al. Effectiveness of enzyme replacement therapy in 1028 patients with type 1 Gaucher disease after 2 to 5 years of treatment: a report from the Gaucher Registry. Am J Med. 2002;113:112-119.

83. Langeveld M, de Fost M, Aerts JM, Sauerwein HP, Hollak CE. Overweight, insulin resistance and type II diabetes in type I Gaucher disease patients in relation to enzyme replacement therapy. Blood Cells Mol Dis. 2008;40(3):428-432.

84. Halperin A, Elstein D, Zimran A. Are symptoms of peripheral neuropathy more prevalent in patients with Gaucher disease? Acta Neurol Scand. 2007;115(4):275-278.

85. Sidransky E, Ginns EI, Westman JA, Ehmann WC. Pathologic fractures may develop in Gaucher patients receiving enzyme replacement therapy. Am J Hematol. 1994;47(3):247-249.

86. Ida H, Rennert OM, Kato S, et al. Severe skeletal complications in Japanese patients with type 1 Gaucher disease. J Inherit Metab Dis. 1999;22(1):63-73.

87. Aviner S, Levy Y, Yaniv I, Cohen IJ. Anaphylactoid reaction to imiglucerase, but not to alglucerase, in a type I Gaucher patient. Blood Cells Mol Dis. 1999;25(2):92-94.

88. Taddei TH, Kacena KA, Yang M, et al. The underrecognized progressive nature of N370S Gaucher disease and assessment of cancer risk in 403 patients. Am J Hematol. 2009;84(4):208-214.

89. Weinreb NJ, Deegan P, Kacena KA, et al. Life expectancy in Gaucher disease type 1. Am J Hematol. 2008;83(12):896-900.

90. de Fost M, Langeveld M, Franssen R, et al. Low HDL cholesterol levels in type I Gaucher disease do not lead to an increased risk of cardiovascular disease. Atherosclerosis. 2009;204(1):267-272.

91. Zimran A, Ilan Y, Elstein D. Enzyme replacement therapy for mild patients with Gaucher disease. Am J Hematol. 2009;84(4): 202-204.

92. Beutler E, Garber AM. Alglucerase for Gaucher's disease: dose, costs and benefits. Pharmacoeconomics. 1994;5(6):453-459.

93. Whittington R, Goa KL. Alglucerase. A pharmacoeconomic appraisal of its use in the treatment of Gaucher's disease. Pharmacoeconomics. 1995;7(1):63-90.

94. Beutler E. Dosage-response in the treatment of Gaucher disease by enzyme replacement therapy. Blood Cells Mol Dis. 2000;26(4): 303-306.

95. Elstein D, Abrahamov A, Hadas-Halpern I, Zimran A. Withdrawal of enzyme replacement therapy in Gaucher's disease. Br J Haematol. 2000;110(2):488-492.

96. Grinzaid KA, Geller E, Hanna SL, Elsas LJ 2nd. Cessation of enzyme replacement therapy in Gaucher disease. Genet Med. 2002;4(6): 427-433.

97. Andersson HC, Charrow J, Kaplan P, et al. Individualization of longterm enzyme replacement therapy for Gaucher disease. Genet Med. 2005;7(2):105-110.

98. Beutler E. Lysosomal storage diseases: natural history and ethical and economic aspects. Mol Genet Metab. 2006;88(3):208-215.

99. Kesselman I, Elstein D, Israeli A, Chertkoff R, Zimran A. National health budgets for expensive orphan drugs: Gaucher disease in Israel as a model. Blood Cells Mol Dis. 2006;37(1):46-49.
100. Zimran A, Loveday K, Fratazzi C, Elstein D. A pharmacokinetic analysis of a novel enzyme replacement therapy with Gene-Activated human glucocerebrosidase (GA-GCB) in patients with type 1 Gaucher disease. Blood Cells Mol Dis. 2007;39(1):115-118.

101. Aviezer D, Brill-Almon E, Shaaltiel Y, et al. A plant-derived recombinant human glucocerebrosidase enzyme - a preclinical and phase I investigation. PLOS ONE. 2009;4(3):e4792.

102. Radin NS. Treatment of Gaucher disease with enzyme inhibitor. Glyco J. 1996;13:153-157.

103. Pastores GM, Elstein D, Hrebícek M, Zimran A. Effect of miglustat on bone disease in adults with type 1 Gaucher disease: a pooled analysis of three multinational, open-label studies. Clin Ther. 2007;29(8): $1645-1654$.

104. Cox TM, Aerts JM, Andria G, et al. The role of the iminosugar N-butyldeoxynojirimycin (miglustat) in the management of type I (non-neuronopathic) Gaucher disease: a position statement. $J$ Inherit Metab Dis. 2003;26(6):513-526.

105. Elstein D, Dweck A, Attias D, et al. Oral maintenance clinical trial with miglustat for type I Gaucher disease: switch from or combination with intravenous enzyme replacement. Blood. 2007;110(7):2296-2301.

106. Schiffmann R, Fitzgibbon EJ, Harris C, et al. Randomized, controlled trial of miglustat in Gaucher's disease type 3. Ann Neurol. 2008;64(5):514-522.

107. Capablo JL, Franco R, de Cabezón AS, Alfonso P, Pocovi M, Giraldo P. Neurologic improvement in a type 3 Gaucher disease patient treated with imiglucerase/miglustat combination. Epilepsia. 2007;48(7):1406-1408.

108. Sawkar AR, Cheng WC, Beutler E, Wong CH, Balch WE, Kelly JW. Chemical chaperones increase the cellular activity of N370S beta-glucosidase: a therapeutic strategy for Gaucher disease. Proc Natl Acad Sci U S A. 2002;99(24):15428-15433.

109. Ron I, Horowitz M. ER retention and degradation as the molecular basis underlying Gaucher disease heterogeneity. Hum Mol Genet. 2005;14:2387-2398.

110. Desnick RJ. Enzyme replacement therapy for Fabry disease: lessons from two alpha-galactosidase A orphan products and one FDA approval. Expert Opin Biol Ther. 2004;4(7):1167-1176.

111. Chang HH, Asano N, Ishii S, Ichikawa Y, Fan JQ. Hydrophilic iminosugar active-site-specific chaperones increase residual glucocerebrosidase activity in fibroblasts from Gaucher patients. FEBS J. 2006;273(17):4082-4092.

112. Tropak MB, Kornhaber GJ, Rigat BA, et al. Identification of pharmacological chaperones for Gaucher disease and characterization of their effects on beta-glucocerebrosidase by hydrogen/deuterium exchange mass spectrometry. Chembiochem. 2008;9(16):2650-2662.

113. Maegawa GH, Tropak MB, Buttner JD, et al. Identification and characterization of ambroxol as an enzyme-enhancement agent for Gaucher disease. J Biol Chem. 2009 Jul 3. [Epub ahead of print].

114. Ratjen F, Wönne R, Posselt HG, Stöver B, Hofmann D, Bender SW. A double-blind placebo controlled trial with oral ambroxol and $\mathrm{N}$-acetylcysteine for mucolytic treatment in cystic fibrosis. Eur $J$ Pediatr. 1985;144(4):374-378.

115. Laoag-Fernandez JB, Fernandez AM, Maruo T. Antenatal use of ambroxol for the prevention of infant respiratory distress syndrome. J Obstet Gynaecol Res. 2000;26(4):307-312.

116. Rigat B, Mahuran D. Diltiazem, a L-type $\mathrm{Ca}(2+)$ channel blocker, also acts as a pharmacological chaperone in Gaucher patient cells. Mol Genet Metab. 2009;96(4):225-232.

117. Elstein D, Abrahamov A, Zimran A. Ethical considerations for enzyme replacement therapy in neuronopathic Gaucher disease. Clin Genet. 1998;4:179-184.

118. Grabowski GA. Perspectives on gene therapy for lysosomal storage diseases that affect hematopoiesis. Curr Hematol Rep. 2003;2(4): $356-362$.

119. Ringdén O, Groth CG, Erikson A, et al. Long-term follow-up of the first successful bone marrow transplantation in Gaucher disease. Transplantation. 1988;46(1):66-70. 
120. Ringdén O, Groth CG, Erikson A, et al. Ten years' experience of bone marrow transplantation for Gaucher disease. Transplantation. 1995;59(6):864-870.

121. Dunbar C, Kohn D. Retroviral mediated transfer of the cDNA for human glucocerebrosidase into hematopoietic stem cells of patients with Gaucher disease. A phase I study. Hum Gene Ther. 1996;7(2):231-253.
122. Barranger JA, Rice EO, Dunigan J, et al. Gaucher's disease: studies of gene transfer to haematopoietic cells. Baillieres Clin Haematol. 1997;10(4):765-778.

123. Enquist IB, Nilsson E, Månsson JE, Ehinger M, Richter J, Karlsson S. Successful low-risk hematopoietic cell therapy in a mouse model of type 1 Gaucher disease. Stem Cells. 2009;27(3):744-752.

\section{Publish your work in this journal}

Biologics: Targets \& Therapy is an international, peer-reviewed journal focusing on the patho-physiological rationale for and clinical application of Biologic agents in the management of autoimmune diseases, cancers or other pathologies where a molecular target can be identified. This journal is indexed on PubMed Central, CAS,

\section{Dovepress}

EMBase, Scopus and the Elsevier Bibliographic databases. The manuscript management system is completely online and includes a very quick and fair peer-review system, which is all easy to use. Visit http://www.dovepress.com/testimonials.php to read real quotes from published authors. 